\title{
An initial performance review of vaginal implant transmitters paired with GPS collars
}

\author{
Justin R. Dion' ${ }^{1}$, Jacob M. Haus ${ }^{1,3^{*}}$ (D), Joseph E. Rogerson² and Jacob L. Bowman
}

\begin{abstract}
Background: The vaginal implant transmitter is an effective tool in the study of neonatal survival rates for cervid species. The latest iterations of the vaginal implant transmitter use Global Positioning Systems and ultra-high frequency telemetry technology to create a self-monitoring system in which researchers receive near instantaneous notifications of parturition events via remote transmission. We deployed ultra-high-frequency radio-linked vaginal implant transmitters on 44 adult female white-tailed deer (Odocoileus virginianus) and assessed their performance and possible benefits to field research.

Results: In 2016,60\% of the females expelled transmitters at the birth sites. Failure to locate a birth site was a result of technological failings (20\%) and premature expulsions (20\%). Following manufacturer updates in 2017, we observed an apparent reduction in technology malfunctions (8\%) but similar rates of premature expulsions (33\%), which resulted in $58 \%$ of radio-linked transmitters expelled at birth sites. We located similar numbers of neonates per device across both years. The likelihood that researchers would locate $>1$ neonate at or near the birth site was greater for radio-linked transmitters than has been reported in studies using traditional vaginal implant transmitters.
\end{abstract}

Conclusions: Radio-linked transmitters allow researchers to increase sample size, expand spatial distribution of study animals, and reduce personnel requirements.

Keywords: Birth site, Neonate, Odocoileus virginianus, Parturition, Vaginal implant transmitter, White-tailed deer

\section{Background}

Estimation of neonate survival is critical to population monitoring and the successful management of whitetailed deer (Odocoileus virginianus) [1-3]. Traditionally, researchers opportunistically captured neonates by either systematical searching of fawning habitat or observing maternal female behavior [4-6]. Opportunistic capture methods are often efficient and can yield a large number of captured neonates. Vaginal implant transmitters (VIT) were developed to enable the location of birth sites and aid in the timely capture of neonatal ungulates [7]. Using a modified version of existing radio telemetry technology, the VIT utilizes a very-high-frequency (VHF) transmitter equipped with a parturition-indicating motion switch and internal spiral antenna. With the advent of VIT

\footnotetext{
*Correspondence: jacob.haus@bemidjistate.edu

3 Present Address: Department of Biology, Bemidji State University, 1500

Birchmont Drive, 218L Sattgast Hall, Bemidji, MN 56601, USA

Full list of author information is available at the end of the article
}

technology, researchers were able to explore new patterns in ungulate reproduction. Researchers could connect individual neonates to their dams, which allowed maternal characteristics (e.g.; age, condition) to be examined as covariates in neonate survival studies [8]. Additionally, neonates could be captured within hours of parturition and enter a survival analysis immediately following birth. Use of opportunistic capture results in a varying age distribution [9], with captured neonates ranging in age from 0 to $\geq 14$ days old $[10,11]$. More recently, researchers examined changes in movement behavior using finescale relocation data from parturient females to identify birth site locations [12, 13], although the transmission and analysis of the data often require a several-day delay before neonates are captures. Varying age distributions can lead to inflated survival rates and a misrepresentation of cause-specific mortality due to missed opportunities to observe early-life mortalities $[9,14]$. Use of VITs meant that all individuals entered the survival window at 
the same age and monitoring began at the earliest possible time.

With traditional VITs, researchers implanted transmitters into gravid females in the winter and then monitored the status of the transmitter via VHF telemetry until parturition in the spring [7]. The transmitter is expelled at the birth site and after a period of inactivity (typically $\sim 2-3 \mathrm{~h}$ ); the motion sensor triggered an event signal (i.e., mortality switch) indicating to the researcher that a parturition event had occurred. The researcher then follows the VHF signal to the location of the parturition site. Original VIT designs had issues with low retention rates $(<50 \%)$ in deer and premature expulsion $[15,16]$. Furthermore, initial designs required suturing of the vulva to retain transmitters within the vaginal canal [7] increasing trauma and risk of infection during device implantation and expulsion. An improved VIT design added silicone wings, which held the device in the vaginal canal closer to the cervix and eliminated the need for sutures [13]. This improved design also had an external antenna, which improved the ability to monitor the status of VIT while implanted in the female and to locate it after expulsion [15]. Retention rate with the updated design increased up to $75 \%$ [15]. Additional updates included adding a temperature and photo-sensor switch [17].

A recent update to traditional VHF VITs pairs the VIT to a GPS collar on the female via ultra-high-frequency (UHF) radio signal communication (radio-linked VIT; hereafter rVIT), eliminating the need for scheduled telemetry monitoring and providing near instantaneous notification of parturition. Our objective was to provide an initial review of the performance and effectiveness of rVIT systems for locating neonatal white-tailed deer. We evaluated the transmitters based on rates of technological failure, retention, the number of neonates located per transmitter, and the rate at which researchers located $>1$ neonate at a birth site.

\section{Study area}

We conducted our research in Sussex County, Delaware, USA. Sussex County is located on the coastal plain bordered on the north by Kent County, Delaware, on the east by the Atlantic Ocean, and on the south and west by Maryland. Elevation ranged from 0 to $21 \mathrm{~m}$ above sea level [18], with little regional variability. Land cover in the study area was $22 \%$ upland forest, $22 \%$ forested wetland, $15 \%$ development, and $41 \%$ agriculture; primary crops were corn, soybeans, and wheat [19].

The estimated deer density in Sussex County was 19.4 deer $/ \mathrm{km}^{2}$ [20]. Sussex County lacks established populations of natural predators of white-tailed deer (e.g., coyote [Canis latrans], bobcat [Lynx rufus], black bear [Ursus americanus]) [21]. Parturition events during our study occurred between 09 May and 23 June in 2016 and 2017 , during which daily temperatures averaged a high of $35^{\circ} \mathrm{C}$ and a low of $3{ }^{\circ} \mathrm{C}[22]$.

\section{Methods \\ Animal capture and handling}

We deployed 44 (2015-2016: $n=20$; 2016-2017: $n=24$ ) rVIT systems (Model M3930U, Advanced Telemetry Systems, Isanti, MN, USA) on adult female white-tailed deer between December and April. We captured deer using rocket nets baited with whole kernel corn [23]. Once captured, we physically restrained and blindfolded each deer before delivering an intramuscular injection of xylazine $(0.5 \mathrm{mg} / \mathrm{kg})$ for chemical immobilization. We estimated age using tooth replacement and wear [24] and deployed rVITs in all females $\geq 1.5$ years old. Although the accuracy of tooth replacement and wear methodology has been criticised for deer $\geq 2$ years old [25], fawns and individuals $\geq 1.5$ years old can be differentiated with reasonable certainty [26]. We implanted the rVITs to a depth of $20 \mathrm{~cm}[6,15]$. Once rVIT implantation was completed, we reversed animals with an intramuscular injection of tolazoline $(4 \mathrm{mg} / \mathrm{kg})$, an antagonist for xylazine. We allowed animals to recover and leave the capture area under their own power.

Given the high rate of conceptus (0.94 [SD $=0.02])$ [27] in the study area among females $\geq 1.5$ years old, we elected to forgo trans-abdominal ultrasound and inserted all females with a transmitter, which is consistent with the previous research $[28,29]$. Operator misinterpretation of conceptus presence introduced a greater potential for error in our study area [30] than an assumption of a $100 \%$ conception rate, and the animal welfare risks associated with increased handling time [31,32] outweighed the risk of implanting a transmitter in a non-gravid female. Furthermore, implants do not appear to result in complications to future reproduction when retained past the typical parturition period [33]. The University of Delaware Institutional Animal Care and Use Committee approved all capture and handling procedures (Protocol $\# 1288$ ).

\section{VIT monitoring}

The rVIT system is equipped with a second antenna (Fig. 1) used to communicate with a GPS collar via UHF. The GPS collar is able to recognize parturition events from the UHF signal, communicate the information to an Iridium satellite network, which then notifies the user via email. Traditionally, studies using standard VIT technology required manual monitoring of VIT signals (typically every $6-8 \mathrm{~h}$ ) throughout the fawning season $[6,15,34]$. The rVIT system eliminates the need for intensive manual monitoring. Following deployment, 


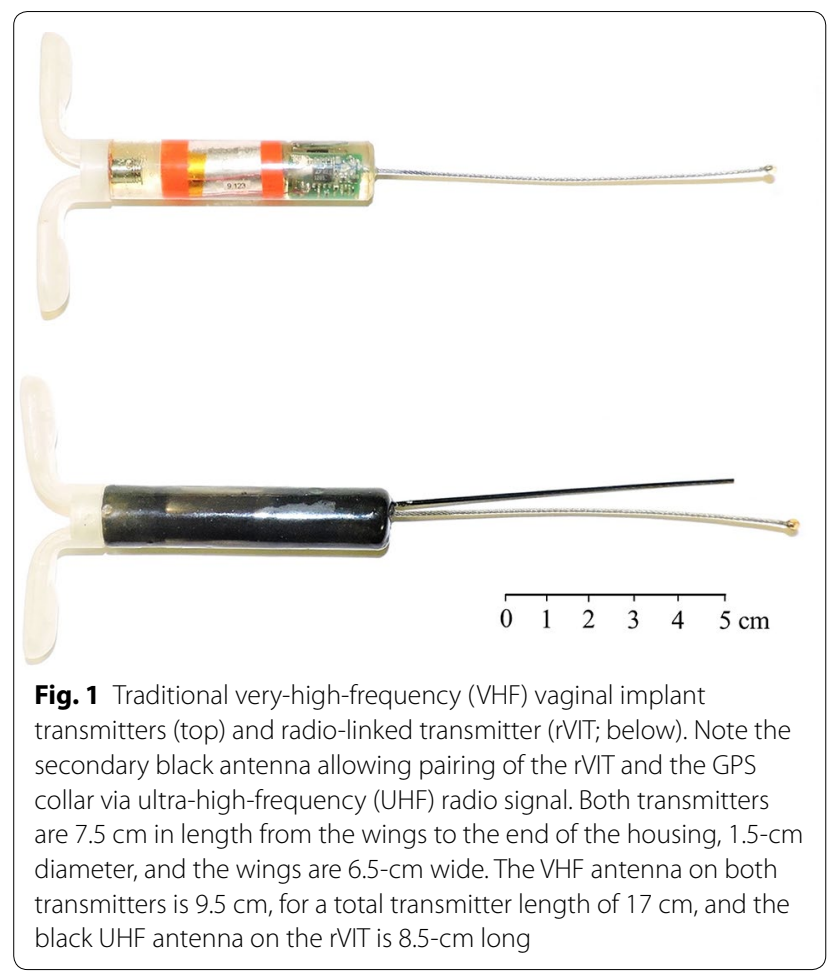

we monitored rVIT daily for any change from the "birth not-yet triggered" designation via an online interface. The rVIT system provides simultaneous monitoring of all deployed devices across the entire study area from a single user interface and nearly instantaneous notification (0-45 min) of a parturition event.

Once an event occurred, we received an email notification describing the event, the collar serial number, and the latitude/longitude coordinates of the transmission. In 2016, we received 2 types of event notifications. A "temperature sensor trigger" notification indicated that the rVIT temperature had dropped below $32{ }^{\circ} \mathrm{C}$, and a "break in communication" notification indicated that the rVIT had been expelled and was out of the 1.8-m range for UHF communication or the rVIT had stopped emitting a signal (e.g., battery death). In 2017, we received both of the above notifications, as well as a "light sensor trigger" event when the photosensor detected light, indicating expulsion of the rVIT had begun [17]. We initiated search efforts after receiving the "temperature sensor trigger" event notification. If we discovered the rVIT outside of any apparent birth site, we searched the area until we found a birth site. If we did not locate the neonates in the immediate vicinity of the birth site, we systematically searched the surrounding area until we found 1 or more neonates. We used a thermal imaging camera (Scout III, FLIR Systems, Wilsonville, OR, USA) to aid in both dayand night-time searches [35].
Table 1 Summary of rVIT results for both $2016(n=20)$ and $2017(n=24)$ neonate capture seasons in Sussex County, Delaware, USA

\begin{tabular}{|c|c|c|c|c|}
\hline \multirow[t]{2}{*}{ Result } & \multicolumn{2}{|c|}{2016} & \multicolumn{2}{|c|}{2017} \\
\hline & $n$ & $\%$ & $n$ & $\%$ \\
\hline Expelled at birth site & 12 & 60.0 & 14 & 58.3 \\
\hline Premature expulsion & 4 & 20.0 & 8 & 33.3 \\
\hline \multicolumn{5}{|l|}{ Technological failure } \\
\hline rVIT link failure & 3 & 15.0 & 0 & 0 \\
\hline GPS collar failure & 1 & 5.0 & 0 & 0 \\
\hline Suspected notification failure & 0 & 0.0 & 2 & 8.3 \\
\hline
\end{tabular}

For evaluation purposes, we assigned each rVIT to one of the 3 potential outcomes: successful expulsion at birth site, premature expulsion, or technological failure (either rVIT link failure or GPS collar failure). We assigned the rVIT link failure designation to systems where we continued to receive transmissions from the GPS collar but did not receive information regarding the rVIT status. Additionally, the GPS collar failure designation included GPS collars that never linked with the satellites and never transmitted data of any kind. We recorded the overall performance results during each year and the number of neonates captured for each rVIT that successfully expelled at a birth site.

\section{Results}

In 2016, we observed a variety of technological malfunctions and failures. Of the 20 rVIT systems deployed, 12 were expelled at the birth site (60\%). In the remaining 8 rVITs, we observed technological failures $(n=3$; $15 \%)$, a collar failure $(n=1 ; 5 \%)$, and premature expulsions $(n=4 ; 20 \%)$. In 2017, following an adjustment of deployment protocols and design alteration by the manufacturer, we observed none of the rVIT failures or GPS collar failures of the previous season (Table 1). Of the 24 systems deployed, 14 expelled at birth sites (58\%) and 8 were expelled prematurely (33\%). Two (8\%) of the rVIT systems from 2017 never reported a birth event, but hourly spatial data from both females showed movements typical of a parturition event and postnatal care. The collars continued to transmit a "birth not-yet triggered" status until we manually deactivated the rVIT link after the typical parturition period (10 July) to conserve collar battery life. We suspect that these rVIT systems failed to communicate a parturition event, but we cannot confirm that parturition occurred. Both females died from anthropogenic causes the following winter, and rVITs were not present in either individual. We classified these 2 observations as suspected notification 
failures (Table 1). Among rVITs expelled at birth sites in both years, we did not find evidence to support a difference $\left(\mathrm{t}_{24}=0.47, P=0.64\right)$ in the mean number of neonates located per VIT between $2016(\bar{x}=1.6, \mathrm{SE}=0.3)$ and $2017(\bar{x}=1.8, \mathrm{SE}=0.3)$. The percentage of instances where we located $>1$ neonate per birth site was greater in 2017 (79\%) than in 2016 (58\%).

\section{Discussion}

The primary benefit of rVIT systems involved the amount of time invested in monitoring efforts prior to parturition. The rVIT self-monitoring system eliminated the need for intensive hourly monitoring regimes leading up to and during the fawning season. The use of rVITs enables researchers to change the scale and scope of their studies in three critical areas; sample size, spatial distribution of study animals, and personnel requirements. By eliminating the need for manual signal monitoring, studies can increase sample sizes beyond what would typically be possible during a 6-8-h monitoring window. To overcome sample size constraints resulting from excessive monitoring costs, previous studies commonly supplemented sample size by incorporating neonates captured via opportunistic methods [36-38]. Reductions in the cost of monitoring would allow sufficient sample sizes of neonates to be captured exclusively utilizing rVIT systems and would eliminate the bias in survival and cause-specific mortality estimates associated with opportunistic capture methods $[9,14]$. Additionally, the ability to monitor devices remotely eliminates many spatial limitations in terms of distance between marked animals on the landscape and also reduces the number of personnel required to monitor transmitters.

In nutrient-rich agricultural areas, the number of fetuses/adult female is generally 2.0 [39, 40]. Given the amount of agriculture and high rate of conceptus, we expected similar rates of fecundity in the study area. The mean number of neonates located per VIT expelled at a birth site ranges from a low of 1.3 (14 neonates/11 VITs) [32] and 1.4 (79 neonates/56 VITs) [42] to a high of 2.0 (14 neonates/7 VITs) [43] for traditional VHF VITs, which is similar to the rates we observed with rVITs (Table 2). The rates of locating $>1$ neonate using rVITs was slightly greater than studies using traditional VITs (52\%) [34], although this statistic is not commonly reported. The increased percentage of capturing $>1$ neonate in 2017 relative to 2016 was likely due to the addition of the photo sensor notification, which allowed for more timely notification of parturition events $[17,45]$ and a reduction in the likelihood and distance that neonates would travel from the birth site before the researcher arrived. While we caution researchers from attempting to locate birth sites immediately following parturition, which may prevent the female from grooming, feeding, and bonding with the neonate [34], near instantaneous notification of parturition events allows researchers to establish more uniform search procedures that likely increase the probability of locating neonates at or near the birth site.

Manufacturer updates following the first year of deployment, such as clarified deployment protocols, improved hardware configuration, and the addition of a photo sensor, resulted in an apparent reduction in the technological failures during the following year. Rates of premature expulsion, however, were similar between years and comparable to previous research using traditional VITs [3, 8, 33, 43]. Given the similar dimensions and wing design, the lack of improved retention rate was not surprising.

The initial cost of rVIT system (approximately $\$ 600$ for rVIT, $\$ 2500$ for compatible GPS collar) is greater than traditional VITs (approximately $\$ 250$ for VIT, $\$ 250$ for VHF collar), although most recent studies utilize the more costly GPS collars over VHF collars regardless of the VIT technology used [34, 38]. Longer-term

Table 2 Summary of reported performance metrics from recent neonate survival research using traditional vaginal implant transmitters relative to results of this study (bottom row) using radio-linked vaginal implant transmitters (VITs) in Sussex County, Delaware, USA

\begin{tabular}{|c|c|c|c|c|c|c|}
\hline Study area & VITs deployed & $\begin{array}{l}\text { Expelled at birth } \\
\text { site }\end{array}$ & Neonates located & $\begin{array}{l}\text { Neonates/birth } \\
\text { site }\end{array}$ & $\begin{array}{l}\text { Premature } \\
\text { expulsions }\end{array}$ & $\begin{array}{l}>1 \text { Neonate } \\
\text { at birth site }\end{array}$ \\
\hline Colorado [3] & 47 & $36(77 \%)$ & 60 & 1.4 & $11(23 \%)$ & - \\
\hline Colorado [8] & 147 & $59(40 \%)$ & 89 & 1.5 & $34(23 \%)$ & - \\
\hline Louisiana [34] & 102 & $46(45 \%)$ & 70 & 1.5 & $3(3 \%)$ & $24(52 \%)$ \\
\hline Missouri [38] & 80 & $64(80 \%)$ & 89 & 1.4 & - & - \\
\hline Alabama [41] & 16 & $11(69 \%)$ & 14 & 1.3 & $1(6 \%)$ & - \\
\hline Connecticut [42] & 103 & $56(54 \%)$ & 79 & 1.4 & - & $25(45 \%)$ \\
\hline Kentucky [44] & 54 & $45(83 \%)$ & 61 & 1.4 & $1(2 \%)$ & - \\
\hline Delaware & 44 & 26 (59\%) & 44 & 1.7 & 12 (27\%) & 18 (69\%) \\
\hline
\end{tabular}


cost savings associated with reductions in personnel and monitoring expenses quickly justify the increased transmitter cost when sample size is large and spatial distribution of the study is wide. We observed no improvement in the number of birth sites successfully located using rVIT systems relative to reported rates from studies using traditional VITs, although rVITs may have improved the probability of locating $>1$ neonate.

\section{Conclusion}

If researchers elect to forgo tans-abdominal ultrasound in the field, obtaining blood samples during adult female capture would allow researchers to confirm conceptus by testing for pregnancy-specific protein B [46, 47]. Knowledge of conceptus status would have allowed us to more accurately assess the 2 cases suspected notification failures, and potential utilize movement behaviors to identify parturition events [12, 13], although presence of a fetus during capture does not necessarily indicate a parturition event will occur. In the future, manufacturers should focus efforts on modifications that improve transmitter retention, since premature expulsion is often the most limiting factor to sample size of captured neonates.

\section{Abbreviations}

VIT: vaginal implant transmitter; GPS: global positioning system,iVHF: very high frequency; rVIT: radio-linked vaginal implant transmitter; UHF: ultra-high frequency.

\section{Acknowledgements}

We are grateful to Kevin Lamp, Miranda Reinson, and Andrew Orlando for assistance with data collection as well as the landowners and sportsman in Sussex County, Delaware for their cooperation. Associate editor and 3 anonymous reviewers provided valuable comments that improved this manuscript.

\section{Authors' contributions}

$J B$ and JR conceived the research objectives and experimental design. JD and $\mathrm{JH}$ collected field data, analyzed the data, and drafted the manuscript, with input from all co-authors. All authors read an approved the final manuscript.

\section{Authors' information}

$J D$ is an assistant big game biologist with the Oregon Department of Fish and Wildlife, $\mathrm{JH}$ is an assistant professor in the Wild life Biology program at Bemidji State University, JR is a program manager for conservation and research at the Delaware Division of Fish and Wildlife, and JB is a professor and department chair in the Entomology and Wildlife Ecology department at the University of Delaware.

\section{Funding}

The Wild life and Sportfish Restoration Grant from the United States Fish and Wildlife Services under Award Number F15AF00929 and the Delaware Department of Natural Resources and Environmental Control provided major funding for this research. The U.S. Department of Agriculture National Institute of Food and Agriculture, Hatch Project DEL00712 and McIntire Stennis DEL00672, also supported this work.

\section{Availability of data and materials}

Data used for the analyses described in the manuscript are available from the authors upon reasonable request.
Ethics approval and consent to participate

Animal handling procedures were approved by the University of Delaware Institutional Animal Care and Use Committee under Permit \#1288.

\section{Consent for publication}

Not applicable.

\section{Competing interests}

The authors declare that they have no competing interests.

\section{Author details}

${ }^{1}$ Department of Entomology and Wildlife Ecology, University of Delaware, Newark, DE 19716, USA. ${ }^{2}$ Delaware Division of Fish and Wildlife, Smyrna, DE 19977, USA. ${ }^{3}$ Present Address: Department of Biology, Bemidji State University, 1500 Birchmont Drive, 218L Sattgast Hall, Bemidji, MN 56601, USA.

Received: 18 July 2019 Accepted: 11 October 2019

Published online: 31 October 2019

\section{References}

1. Burroughs JP, Campa H, Winterstein SR, Rudolph BA, Moritz WE. Causespecific mortality and survival of white-tailed deer fawns in southwestern lower Michigan. J Wild Manag. 2006;70:743-51.

2. Hiller TL, Campa H, Winterstein SR, Rudolph BA. Age-specific survival and space use of white-tailed deer in southern Michigan. Mich Acad. 2008:38:101-19.

3. Bishop CJ, Anderson CR, Walsh DP, Bergman EJ, Kuechle P, Roth J. Effectiveness of a redesigned vaginal implant transmitter in mule deer. J Wild Manag. 2011;75:1797-806.

4. Huegel CN, Dahlgren RB, Gladfelter HL. Use of doe behavior to capture white-tailed deer fawns. Wildl Soc Bull. 1985;13:287-9.

5. Ballard WB, Whitlaw HA, Young SJ, Jenkins RA, Forbes GJ. Predation and survival of white tailed deer fawns in northcentral New Brunswick. J Wild Manag. 1999;63:574-9.

6. Carstensen M, Delgiudice GD, Sampson BA. Using doe behavior and vaginal implant transmitters to capture neonate white-tailed deer in north-central Minnesota. Wildl Soc Bull. 2003;31:634-41.

7. Garrott R, Bartmann R. Evaluation of vaginal implants for mule deer. J Wild Manag. 1984;48:646-8.

8. Bishop CJ, Freddy DJ, White GC, Watkins BE, Stephenson TR, Wolfe LL. Using vaginal implant transmitters to aid in capture of mule deer neonates. J Wild Manag. 2010;71:945-54.

9. Chitwood MC, Lashley MA, DePerno CS, Moorman CE. Considerations on neonatal ungulate capture method: potential for bias in survival estimation and cause specific mortality. Wildlife Biol. 2017; wlb.00250.

10. Grovenburg TW, Klaver RW, Jenks JJ. Survival of white-tailed deer fanws in the grasslands of the northern great plains. J Wild Manag. 2012;76:944-56.

11. Duquette JF, Belant JL, Svoboda NJ, Beyer DE, Lederle PE. Effects of maternal nutrition, resource use and multi-predator risk on neonatal white-tailed deer survival. PLoS ONE. 2014;9:e100841.

12. Peterson ME, Anderson CR Jr, Alldredge WM, Doherty PF Jr. Using maternal mule deer movements to estimate timing of parturition and assist fawn captures. Wildl Soc Bull. 2018;42:616-21.

13. Severud WJ, Del Giudice G, Obermoller TR, Enright TA, Wright RG, Forester JD. Using GPS collars to determine parturition and cause-specific mortality of moose calves. J Wild Manag. 2015;39:616-25.

14. Gilbert SL, Lindberg MS, Hundertmark KJ, Person DK. Dead before detection: addressing the effects of left truncation on survival estimation and ecological inference for neonates. Methods Ecol Evol. 2014;5:992-1001.

15. Bowman JL, Jacobson HA. An improved vaginal-implant transmitter for locating white-tailed deer birth sites and fawns. Wildl Soc Bull. 1998;26:295-8.

16. Nelson TA. Production and survival of white-tailed deer fawns on Crab Orchard National Wildlife Refuge. 1984; Thesis, South Illinois University, Carbondale, USA.

17. Cherry MJ, Nelson ML, Warren RJ, Connor LM. Photo sensors increase likelihood of detection of expelled vaginal implant transmitters. Wild Soc Bull. 2013;37:846-50. 
18. United States Geological Survey. 3D Elevation Program. 2019. https:// www.usgs.gov/core-science-systems/ngp/3dep/about-3dep-productsservices. Accessed 27 Feb 2019.

19. National Agricultural Statistical Service. Census of agriculture county profile: Sussex county, Delaware. 2012. https://www.agcensus.usda.gov/ Publications/2012/Online_Resources/County_Profiles/Delaware/cp100 05. Accessed 2 Mar 2016.

20. Delaware Division of Fish and Wildlife. Delaware deer density and population estimates. 2009. http://www.dnrec.delaware.gov/fw/Hunting/Pages/ Deerlnfo.aspx. Accessed 6 May 2014.

21. Dion JR. Neonate survival and spatial ecology of adult female whitetailed deer in the functional absence of predators. 2018; Master's Thesis, University of Delaware, Newark, USA.

22. National Climatic Data Center. Daily weather summaries, Georgetown, Delaware station. 2017. https://www.ncdc.noaa.gov/data-access/landbased-station-data. Accessed 20 Nov 2017

23. Schemnitz SD, Batcheller GR, Lovallo MJ, White HB, Fall MW. Capturing and handling wild animals. In: Silvy NJ, editor. The Wild life Techniques Manual, vol. 1. 7th ed. Baltimore: The Johns Hopkins University Press; 2012. p. 64-117.

24. Severinghaus $\mathrm{CW}$. Tooth development and wear as criteria of age in white-tailed deer. The J Wild Manag. 1949;13:195-216.

25. Storm DJ, Samuel MD, Rolly RE, Beissel T, Richards BJ, Van Deelen TR. Estimating ages of white-tailed deer: age and sex patterns of error using tooth wear-and-replacement and consistency of cementum annuli. Wildl Soc Bull. 2014;38:1849-56.

26. Gee KL, Holman JH, Causey MK, Rossi AN, Armstrong JB. Aging whitetailed deer by tooth replacement and wear: a critical evaluation of a time-honored tradition. Wildl Soc Bull. 2002;30:387-93.

27. Jennings B, Bowman JL, Tymkiw EL. A spatially explicit model of the white-tailed deer population in Delaware. Hum-Wildl Interact. 2014;8:195-209.

28. Kilgo JC, Ray HS, Vukovich M, Goode MJ, Ruth C. Predation by coyotes on white-tailed deer neonates in South Carolina. J Wild Manag. 2012;76:1420-30.

29. Chitwood MC, Lashley MA, Kilgo JC, Pollock KH, Moorman CE, DePerno CS. Do biological and bedsite characteristics influence survival of neonatal white-tailed deer? PLOS ONE. 2015;10:e0119070.

30. Duquette JF, Belant JL, Beyer DE, Svoboda NJ. Comparison of pregnancy detection methods in live white-tailed deer. Wildl Soc Bull. 2012;36:115-8.

31. Beringer J, Hansen LP, Wilding W, Fischer J, Sheriff SL. Factors affecting capture myopathy in white-tailed deer. J Wild Manag. 1996;30:373-80.

32. Haulton SM, Porter WF, Rudolph BA. Evaluating 4 methods to capture white-tailed deer. Wildl Soc Bull. 2001;29:255-64.

33. Seward NW, Maehr DS, Gassett JW, Cox JJ, Larkin JL. From the field: field searches versus vaginal implant transmitters for locating elk calves. Wild Soc Bull. 2010;33:751-5.
34. Shuman RM, Cherry MJ, Simoneaux TN, Dutoit EA, Kilgo JC, Chamberlain MJ, Miller KV. Survival of white-tailed deer neonates in Louisiana. J Wild Manag. 2017:8:834-45.

35. Ditchkoff SS, Raglin JB, Smith JM, Collier BA. From the field: capture of white-tailed deer fawns using thermal imaging technology. Wildl Soc Bull. 2005;33:1164-8.

36. Grovenburg TW, Swanson CC, Jacques CN, Klaver RW, Brinkman TJ, Burris BM, DePerno CS, Jenks JA. Survival of white-tailed deer neonates in Minnesota and South Dakota. J Wild Manag. 2011;75:213-20.

37. Warbington $\mathrm{CH}$, Van Deelen TR, Norton AS, Stenglein JL, Storm DJ, Martin KJ. Cause-specific neonatal mortality of white-tailed deer in Wisconsin, USA. J Wild Manag. 2017;81:824-33.

38. Wright CA, McRoberts JT, Wiskirchen KH, Keller BJ, Millspaugh JJ. Landscape-scale habitat characteristics and neonatal white-tailed deer survival. J Wild Manag. 2019;1:1401-14.

39. Nixon CM. Productivity of white-tailed deer in Ohio. Ohio J Sci. $1971 ; 71: 21-225$.

40. Haugen AO. Reproductive performance of white-tailed deer in lowa. J Mammal. 1975;56:151-9.

41. Jackson AM, Ditchkoff SS. Survival estimates of white-tailed deer fawns at Fort Rucker, Alabama. Am Midl Nat. 2013;170:184-90.

42. Kilburn JE. Spatial variability in abundance, detectability and survival of white-tailed deer across a heterogeneous landscape of fear. 2018; Master's Thesis. University of Connecticut, Storrs, Connecticut, USA.

43. Swanson CC, Jenks JJ, DePerno CS, Klaver RW, Osborn RG, Tardiff JA. Does the use of vaginal-implant transmitters affect neonate survival rate of white-tailed deer Odocoileus virginianus? Wildl Biol. 2008;14:272-9.

44. McDermott JR. Survival and cause-specific mortality of white-tailed deer (Odocoileus virginianus) neonates in a southeastern Kentucky population. 2017; Master's Thesis. University of Kentucky, Lexington, Kentucky, USA.

45. Newbolt CH, Ditchkoff SS. Effects of environmental conditions on performance of vaginal implant transmitters. J Wild Manag. 2009;73:303-5.

46. Wood AK, Short RE, Darling A, Dusek GL, Sasser RG, Ruder CA. Serum assays for detecting pregnancy in mule and whitetailed deer. J Wild Manag. 1986;50:684-7.

47. Duquette JF, Belant JL, Beyer DE, Svoboda NJ. Comparison of pregnancy detection methods in live white-tailed deer. Wildl Soc Bull. 2012;36:115-8.

\section{Publisher's Note}

Springer Nature remains neutral with regard to jurisdictional claims in published maps and institutional affiliations.
Ready to submit your research? Choose BMC and benefit from:

- fast, convenient online submission

- thorough peer review by experienced researchers in your field

- rapid publication on acceptance

- support for research data, including large and complex data types

- gold Open Access which fosters wider collaboration and increased citations

- maximum visibility for your research: over $100 \mathrm{M}$ website views per year

At BMC, research is always in progress.

Learn more biomedcentral.com/submissions 